Gut, 1982, 23, 202-210

\title{
Intestinal permeability in coeliac disease: the response to gluten withdrawal and single-dose gluten challenge
}

\author{
I HAMILTON, I COBDEN, J ROTHWELL, AND A T R AXON \\ From the Gastroenterology Unit, The General Infirmary, Leeds
}

SUMMARY Intestinal permeability has been studied in 21 patients with coeliac disease in relapse and after gluten withdrawal using an oral test of intestinal permeability based on the simultaneous oral administration of two probe molecules. The increased absorption of the larger molecule (cellobiose) and the decreased absorption of the smaller (mannitol) found in untreated coeliac disease both returned to normal within five months of starting treatment, the abnormality in cellobiose absorption correcting more rapidly than that of mannitol. After exposure to a single oral dose of gluten, the intestinal permeability of six patients with treated coeliac disease became transiently abnormal with an increased absorption of cellobiose, returning to normal within one week. The possible structural and functional implications of these findings are discussed. The cellobiose/mannitol ratio appears to be of value in assessing the response to gluten withdrawal in coeliac disease, and also in monitoring patients who are already established on a gluten free diet by detecting dietary lapses and 'non-responding coeliac disease'. It may also offer an alternative to jejunal biopsy in patients subjected to gluten challenge.

The abnormal intestinal permeability of untreated coeliac disease is characterised by a reduced absorption of small hydrophilic molecules ${ }^{1}$ with a paradoxical increase in absorption of larger molecules. ${ }^{2}{ }^{3} \mathrm{We}$ have used the simultaneous oral administration of two water-soluble probe molecules, mannitol (molecular radius $0.4 \mathrm{nM}$ ) and cellobiose (molecular radius 0.5 $\mathrm{nM}$ ) to demonstrate these changes, and have shown that patients with coeliac disease excrete more cellobiose and less mannitol in their urine than controls, after oral ingestion of these molecules in hypertonic solution. ${ }^{4}$ Expression of the result as a ratio of cellobiose recovery to mannitol recovery allows clear separation of normal subjects from coeliacs, a finding confirmed by others using a similar test system. ${ }^{5}$ The absorption of mannitol from the normal small bowel is $10-200$ fold greater than that of cellobiose, suggesting, in the absence of active transport, ${ }^{36}$ that, while mannitol may be absorbed through classical transcellular aqueous pores, cellobiose is excluded by its size. The effective pore radius must, therefore, lie between 0.4 and $0.5 \mathrm{nM}$, in agreement with earlier estimates, ${ }^{7}{ }^{8}$ and much smaller than the estimate of $0.8 \mathrm{nM}$ by Fordtran et al, ${ }^{9}$

* Address for correspondence: Dr I Hamilton, Gastroenterology Unit, The General Infirmary, Leeds.

Received for publication 17 August 1981 whose calculations relied on the complete failure of mannitol absorption, while we can confirm the previously reported significant absorption of mannitol in man. ${ }^{40}$ The paradoxical changes in absorption of the two probe molecules which occur in coeliac disease also suggest that they are absorbed through different routes, and the presence of more than one route of diffusion of hydrophilic molecules across cell membranes has been previously postulated. ${ }^{11}$

The alternative route of absorption for large molecules may be through the intercellular 'tight junction" or through epithelial discontinuities such as the cell extrusion zones of the villous tips, ${ }^{12}$ and the increased cellobiose absorption in disease may reflect non-specific epithelial injury, increased cell shedding, or changes in the tight junction. The reduced absorption of mannitol may result from a reduction in the number of aqueous pores available for diffusion secondary to a reduction in absorptive surface area. These permeability changes of coeliac disease are similar to those occurring in a rat nematode infestation, in which the histological lesion resembles that of coeliac disease. ${ }^{13}$

The simultaneous administration of two probe molecules, and expression of the urinary recoveries as a ratio, reduces the influence of factors other than intestinal absorption - for example, gastric emptying, intes- 
tinal transit, and renal function, on the result, and we have demonstrated the reliability of this test as a screening test for proximal small bowel disease. ${ }^{14}$ The changes in intestinal permeability occurring during treatment of coeliac disease have not been described, and this paper demonstrates the use of the cellobiose/mannitol recovery ratio in monitoring the changes of intestinal permeability after treatment of coeliac disease with a gluten free diet, and after a single dose gluten challenge given to six coeliacs in remission.

\section{Methods}

\section{PATIENTS}

Response to gluten withdrawal

Eighty-nine individuals were studied, these comprised: Untreated group Twenty-one patients, mean age 41 years (range 16-64), had partial (nine) or subtotal (12) villous atrophy on jejunal biopsy. Three had been diagnosed as having coeliac disease several years previously on the basis of an abnormal jejunal biopsy and had made a satisfactory clinical response to a gluten free diet, but were studied at a time of recurrent symptoms associated with dietary relaxation. The remaining 18 were newly diagnosed. All patients were treated by gluten withdrawal, and all those with symptoms responded clinically. Twelve have had a post-treatment biopsy which has confirmed histological response, and nine have refused a further biopsy. Intestinal permeability was measured in each of these patients before, and at a mean time of four months (range three to eight months) after the institution of a gluten free diet. Permeability changes in 10 of the patients were studied more closely by testing them initially weekly, and subsequently at increasing intervals.

Previously treated group Ten patients were alreády established on a gluten free diet, a diagnosis of coeliac disease having previously been made on the basis of an abnormal jejunal biopsy and a satisfactory clinical response to treatment. Seven had shown a histological response on a post-treatment jejunal biopsy, and three had refused further biopsy. The mean age of these patients was 37 years (range 19-42 years) and the mean duration of treatment was 6.5 years (range three-14 years).

Non-responding group These three patients had been shown to have partial or sub-total villous atrophy on jejunal biopsy, and had not responded clinically or histologically to a gluten free diet. The diagnosis of lymphoma has been confirmed in one, and is suspected in the other two.

Control group Fifty-five patients were identified who had carried out the test and had subsequently been shown to have a normal jejunal biopsy, and no evidence of significant gastrointestinal pathology. These patients form the control population.
Gluten challenge

Six patients with coeliac disease who were well controlled on a gluten free diet agreed to take part. Their mean age was 50.6 years (range $40-64$ years) and they had been treated for a mean of two years (range six months-six years). Each patient was tested one day before, and daily for five days after a single oral dose of $30 \mathrm{~g}$ gluten taken in milk at bedtime, otherwise continuing with their gluten free diet.

Three normal controls were tested in the same way, taking $30 \mathrm{~g}$ of gluten, while on a normal diet.

\section{PROCEDURE}

The test drink comprised $5 \mathrm{~g}$ cellobiose and $2 \mathrm{~g}$ mannitol dissolved in $100 \mathrm{ml}$ water. Twenty grams of lactose and $20 \mathrm{~g}$ sucrose were added to increase the osmolality of the solution to approximately $1500 \mathrm{mOsmol}$, which enhances the cellobiose absorption and increases the discrimination between normal and abnormal mucosae. ${ }^{12}$

After an overnight fast, subjects emptied their bladder to provide a baseline urine sample, and drank 100 $\mathrm{ml}$ test solution undiluted. All urine passed over the next five hours was collected into $25 \mu \mathrm{M}$ thiomersal.

Mannitol was assayed by a spectophometric method, with an accuracy of $94-106 \%$ and the coefficient of variation was $\pm 2.5 \% .{ }^{15}$ Cellobiose was assayed by quantitative paper chromatography..$^{16}$ The accuracy of the assay technique was $94-110 \%$ and coefficient of variation $\pm 2.0 \%$ for both samples and standard aqueous solutions. ${ }^{15}$ The urinary recovery of each molecule was expressed as the percentage of the administered dose recovered, and the cellobiose/mannitol percentage recovery ratio was the ratio of the percentage quantities of each probe molecule recovered.

This expression of the cellobiose/mannitol ratio differs from that used in our previous papers, ${ }^{4}{ }^{13-15}$ which was the ratio of the absolute quantities of each probe molecule recovered, but has the advantage of automatically relating the recovery of each of the molecules to the administered dose.

Statistical comparisons were performed using the Mann-Whitney U test.

\section{Results}

RESULTS IN NORMAL CONTROLS (Table)

Mean cellobiose recovery was $0.32 \pm 0.20 \%$, mean mannitol recovery $19.6 \pm 8.3 \%$. The mean cellobiose/mannitol recovery ratio in normal subjects is $0.0172 \pm 0.009$, with an absolute range of $0 \cdot 002-0.04$. Distribution is skewed towards lower values, however, and the accepted upper limit of the normal range is 0.03 . 
Table Urinary recoveries of cellobiose and mannitol, and cellobiose/mannitol recovery ratios, in controls, patients with newly diagnosed coeliac disease before and after treatment, patients with previously treated coeliac disease, and patients with non-responding coeliac disease

\begin{tabular}{lccc}
\hline & $\begin{array}{l}\text { \% Cellobiose } \\
\text { recovery } \\
\text { (mean } \pm S D)\end{array}$ & $\begin{array}{l}\text { \% Mannitol } \\
\text { recovery } \\
\text { (mean } \pm S D)\end{array}$ & $\begin{array}{l}\text { Cellobiose } \\
\text { mannitol ratio } \\
\text { (mean } \pm S D)\end{array}$ \\
\hline $\begin{array}{l}\text { Controls } \\
(\mathrm{n}=55)\end{array}$ & $0.32 \pm 0.20$ & $19.6 \pm 8.30$ & $0.0172 \pm 0.009$ \\
\hline $\begin{array}{l}\text { Coeliac disease } \\
\text { newly diagnosed } \\
(\mathrm{n}=21)\end{array}$ & & & \\
$\begin{array}{l}\text { Before treatment } \\
\text { After treatment }\end{array}$ & $0.96 \pm 0.61$ & $8.38 \pm 6.32$ & $0.23 \pm 0.09$ \\
\hline $\begin{array}{l}\text { Previously treated } \\
(\mathrm{n}=10)\end{array}$ & $0.57 \pm 0.50$ & $14.63 \pm 4.94$ & $0.032 \pm 0.02$ \\
\hline $\begin{array}{l}\text { Non-responsive } \\
(\mathrm{n}=3)\end{array}$ & $0.66 \pm 0.22$ & $10.50 \pm 5.60$ & $0.09 \pm 0.056$ \\
\hline
\end{tabular}

RESULTS IN UNTREATED COELIAC DISEASE AND EFFECT OF GLUTEN WITHDRAWAL

Before treatment, mean cellobiose recovery was 0.96 $\pm 0.61 \%$, mannitol recovery $8.36 \pm 6.32 \%$, and the mean ratio $0.23 \pm 0.09$. Only one patient had a cellobiose/mannitol recovery ratio within the absolute range of normal and none was within the accepted normal range. All values differed significantly from con- . trols $(\mathrm{P}=<0.05$. Table).

After treatment mean cellobiose recovery in these patients fell to $0.29 \pm 0.24 \%(\mathrm{P}=<0.05)$, mannitol recovery rose to $22.1 \pm 14 \%(\mathrm{P}=<0.05)$, and the mean ratio fell to $0.019 \pm 0.01(\mathrm{P}=<0.05)$. None of these mean post-treatment values differed significantly from controls (Table).

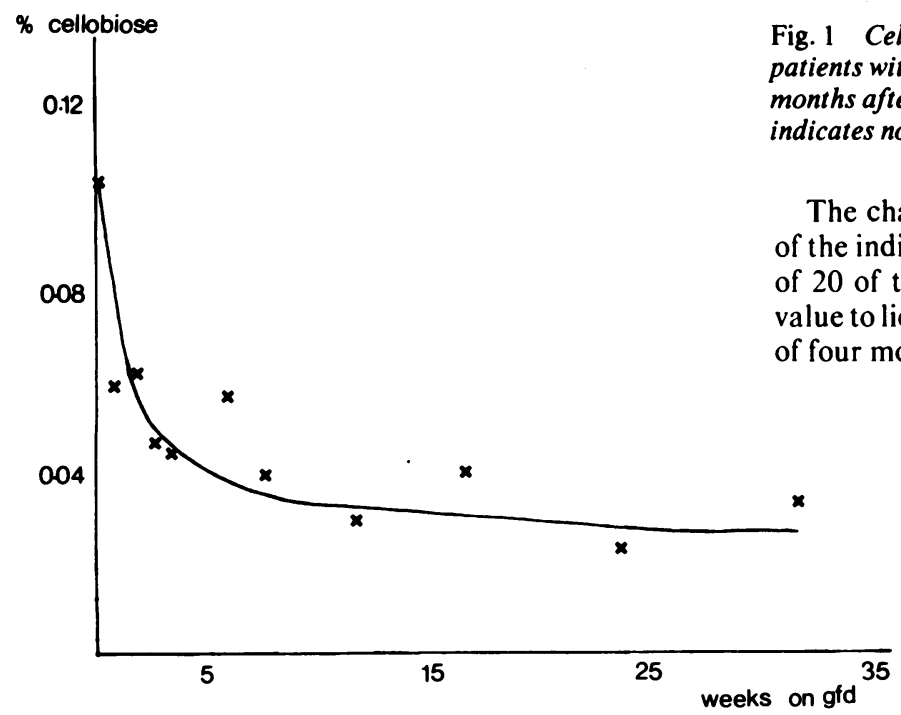

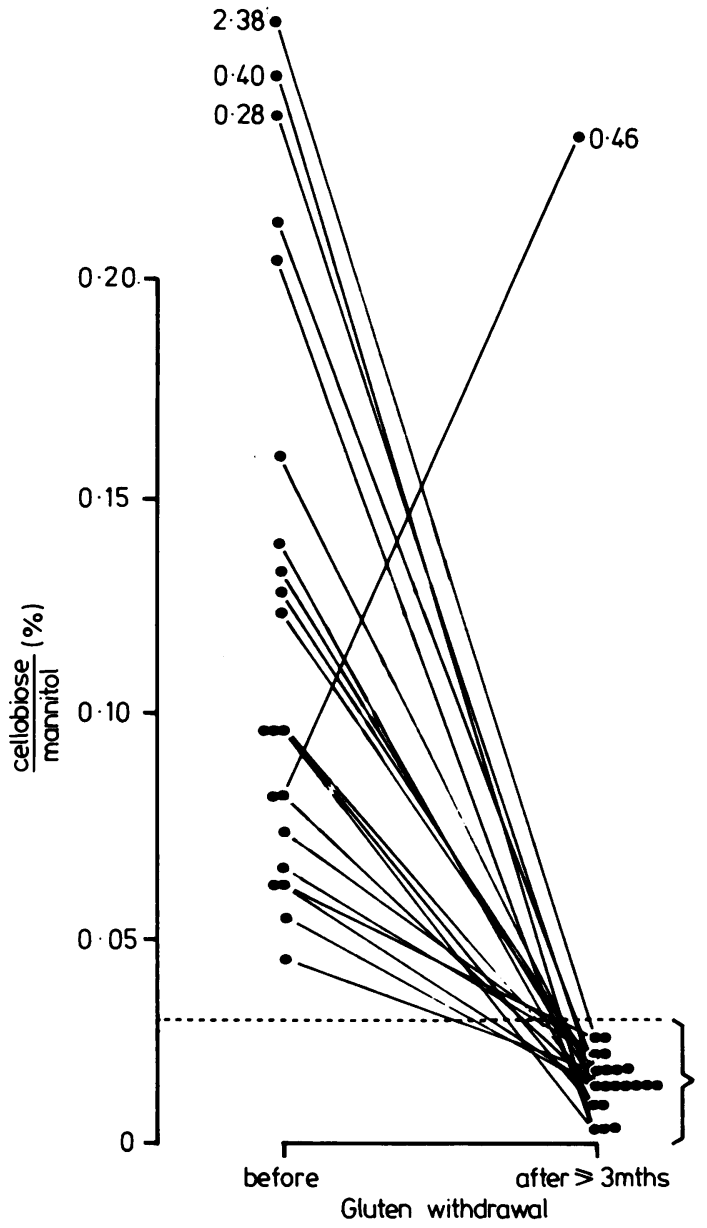

Fig. 1 Cellobiose/mannitol percentage recovery ratio in 21 patients with coeliac disease before, and a minimum of three months after treatment with a gluten free diet. Bracket indicates normal range.

The changes in cellobiose/mannitol recovery ratios of the individual patients are shown in Fig. 1. The ratio of 20 of the 21 patients fell from a clearly abnormal value to lie within the normal range after a mean period of four months' dietary treatment.

Fig. 2 Mean cellobiose recovery in 10 patients with coeliac disease against duration of treatment with a gluten free diet. 
TIME COURSE OF RESPONSE TO GLUTEN WITHDRAWAL

The mean cellobiose recovery fell sharply from an initially high value, the fall occurring over the first eight-10 weeks of the diet (Fig. 2). The mean mannitol recovery rose more slowly, reaching a plateau over the first 20 weeks of treatment (Fig. 3). Mean recovery of each of the probe molecules remained substantially unchanged thereafter.

The cellobiose/mannitol recovery ratio (Fig. 4) of all

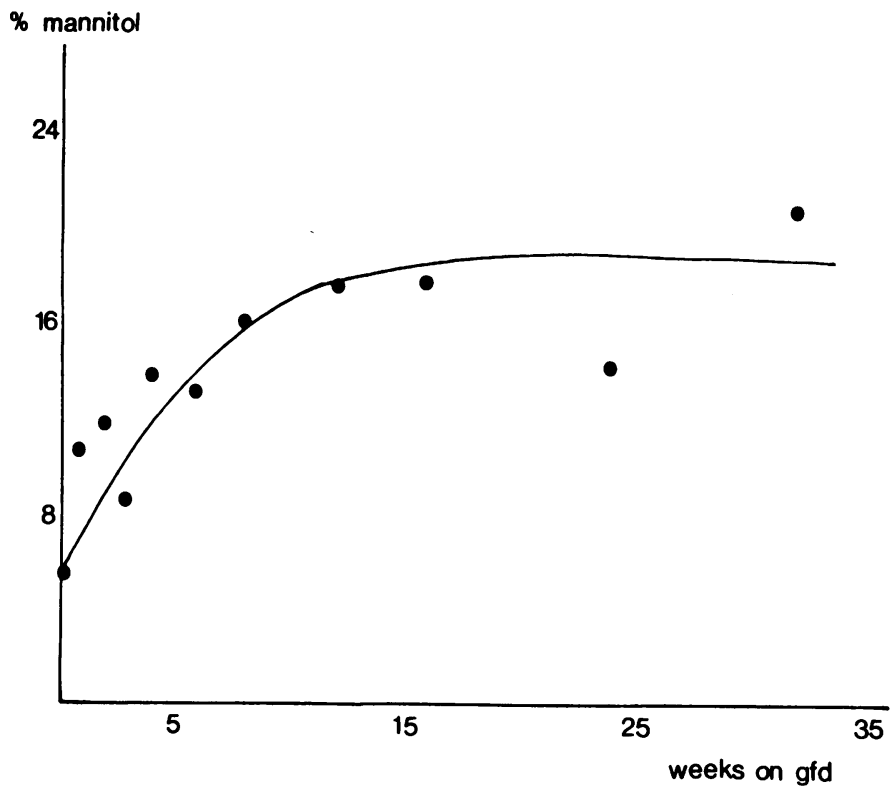

Fig. 3 Mean mannitol recovery in 10 patients with coeliac disease against duration of treatment with a gluten free diet.

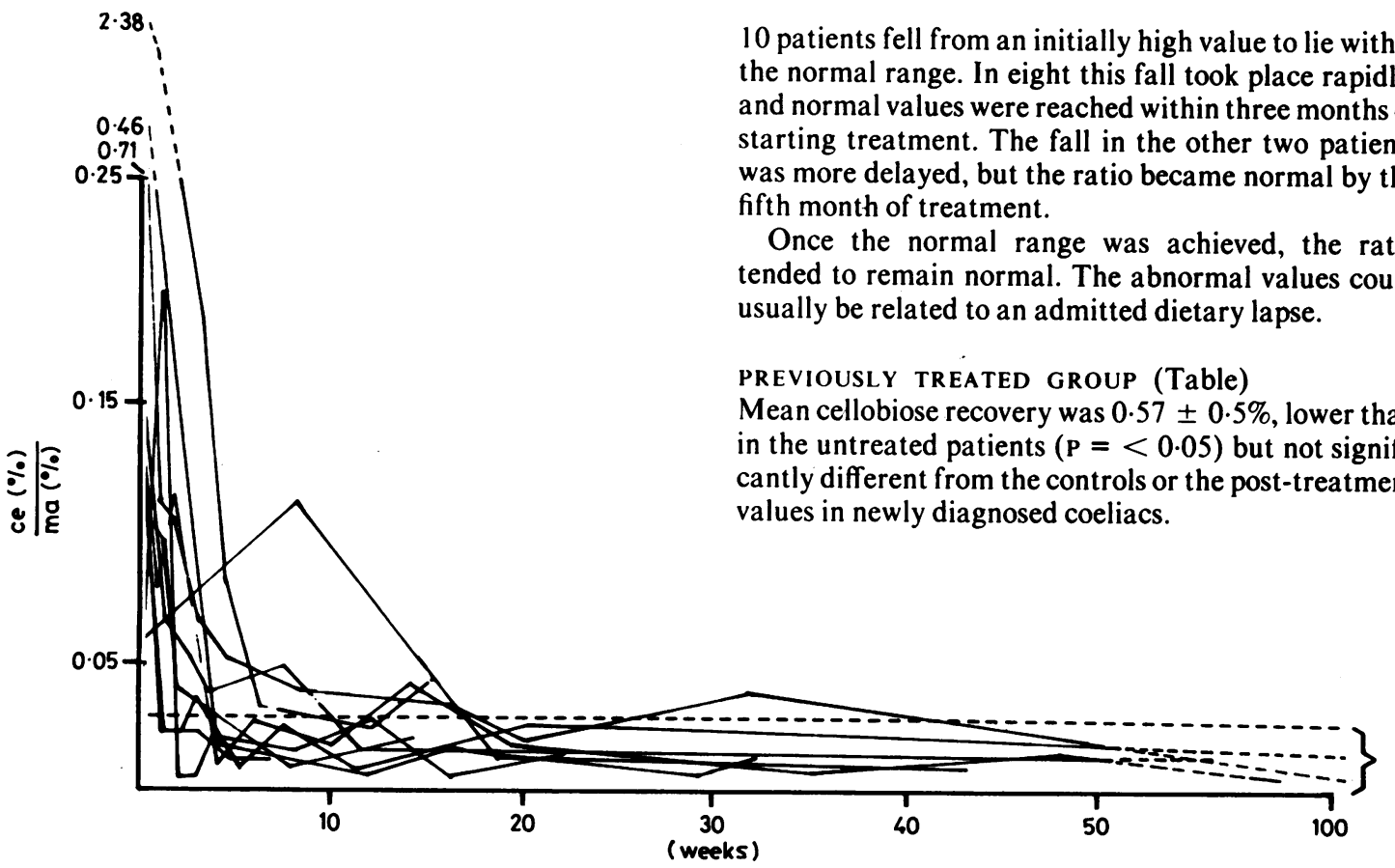

Fig. 4 Cellobiose/mannitol percentage recovery ratios of 10 patients with coeliac disease, against duration of treatment with a gluten free diet. Bracket indicates normal range. 
Mean mannitol recovery was $14.63 \pm 4.94 \%$, higher than in untreated patients $(P=<0.002)$, and lower than controls $(\mathrm{P}=<0.05)$ or newly diagnosed coeliacs after treatment $(P=<0.05)$.

Mean cellobiose/mannitol recovery ratio was 0.032 \pm 0.02 , lower than in untreated patients $(P=<0.05)$, but not significantly higher than in controls or newly diagnosed coeliacs after treatment.

NON-RESPONDING GROUP (Table)

Six tests were performed on three patients during treatment with a gluten free diet to which they did not respond clinically or histologically.

Mean cellobiose recovery was $0 \cdot 66 \pm 0 \cdot 22 \%$, which is higher than that found in controls or treated patients of either group ( $\mathrm{P}=<0.05)$ but not significantly different from that of untreated patients. Mannitol recovery was $10.5 \pm 5.6 \%$ lower than in treated patients $(\mathrm{P}=<0.05)$ but not significantly different from untreated patients. The cellobiose/mannitol recovery ratio was $0.09 \pm 0.056$, and again was higher than in treated $(\mathrm{P}=<0.05)$ but not untreated patients - that is, treated non-responders behaved like untreated coeliacs.

\section{GLUTEN CHALLENGE}

Before taking gluten, mean mannitol recovery in six patients was $19.8 \pm 11.7 \%$, mean cellobiose recovery
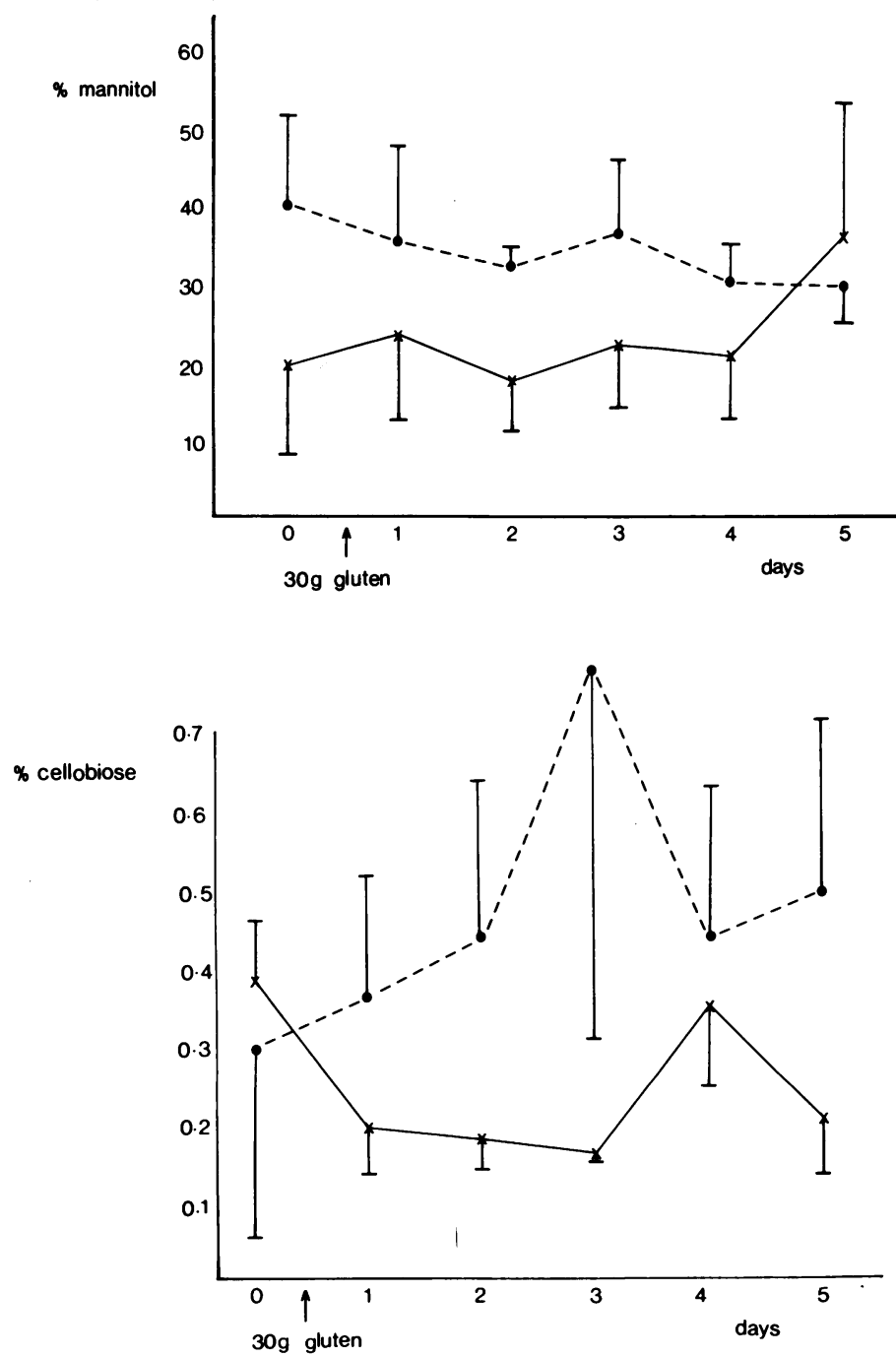

Fig. 5 Mean $(+$ or $-S D)$ urinary recovery of mannitol in six patients with coeliac disease $\left(\mathbf{0}_{-}-\mathbf{Q}^{\prime}\right)$ and three normal controls $(X$ $X)$ before and after gluten challenge:
Fig. 6 Mean $(+$ or $-S D)$ urinary recovery of cellobiose in six patients with coeliac disease (-..- $)$ and three normal controls $(X-X)$ before and after gluten challenge. 


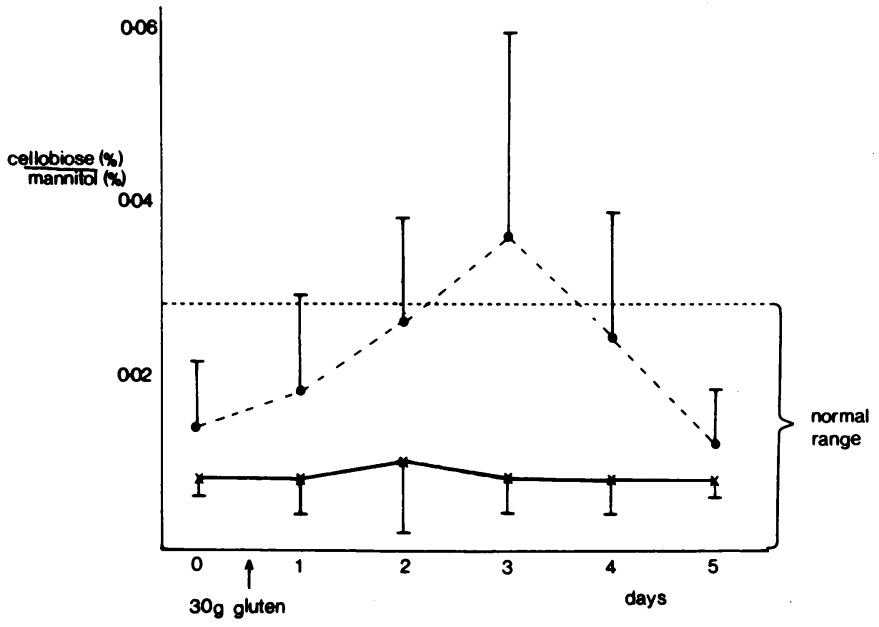

Fig. 7 Mean $( \pm S D$ ) cellobiose/mannitol percentage recovery ratio in six patients with coeliac disease (- $(--)$ ) and three normal controls $(X-X)$ before and after gluten challenge.

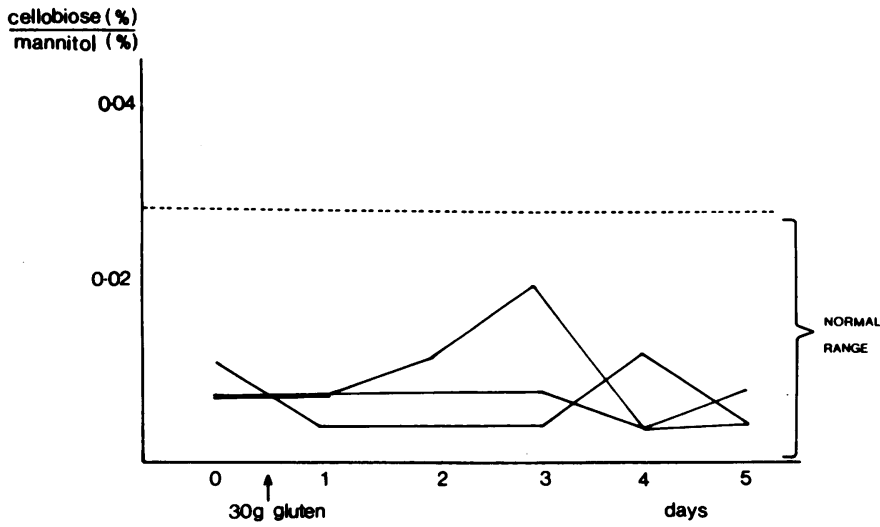

Fig. 8 Cellobiose/mannitol percentage recovery ratios in six patients with coeliac disease before and after gluten challenge.

Fig. 9 Cellobiose/mannitol percentage recovery ratios in three normal controls before and after gluten challenge. 
$0.30 \pm 0.28 \%$, and the cellobiose/mannitol recovery ratio was $0.035 \pm 0.02$. All values were similar to the normal controls and the ratio was within the normal range.

After ingestion of a single dose of $30 \mathrm{~g}$ commercial gluten, there was little change in mannitol recovery in either patients or controls (Fig. 5), while cellobiose recovery showed a progressive rise, reaching a peak after three days and falling again by day 5 (Fig. 6), a change not seen in controls. Because of the wide variation between individuals and the small group of patients studied these results did not achieve statistical significance.

The mean cellobiose/mannitol recovery ratio in patients rose progressively over the three days after gluten ingestion to an abnormal value of $0.037 \pm 0.023$ on day 3 , and fell to $0.014 \pm 0.006$ by day 5 (Fig. 7). The value on day 3 was significantly greater than that before gluten $(\mathrm{P}=<0.05)$, and five days after gluten $(\mathrm{P}=<0.05)$.

Of greater importance was the change in individual ratios (Fig. 8). Each patient had a normal ratio before gluten challenge, but in each case the ratio rose to reach a clearly abnormal value between the second and fourth day after taking gluten. The ratio for all patients had returned to normal by day 5 .

None of the controls showed any significant change in cellobiose/mannitol recovery ratio after gluten, and the control value on day 3 differed significantly from that of patients $(P=<0.05)$ (Fig. 9). The mean ratio of controls was consistently within the range 0.008-0.01.

\section{Discussion}

This simple and non-invasive test of intestinal permeability has enabled us to demonstrate the improvement in one aspect of small bowel function which occurs during the first six months of treatment of coeliac disease with a gluten free diet, and also demonstrates the transient abnormality of permeability resulting from a single exposure to gluten in susceptible individuals.

The abnormal passive permeability of the small intestine in coeliac disease rapidly returns to normal after treatment with a gluten free diet, as is shown by the change in the cellobiose/mannitol percentage recovery ratio (Figs. 1 and 4). The only patient in whom the ratio did not return to normal was asymptomatic at the time of diagnosis, and has subsequently admitted that she did not adhere to a strict gluten free diet. Patients already established on a gluten free diet had results which were intermediate between normals and untreated coeliacs, possibly indicating a less rigid dietary adherence, since they had been on treatment for considerably longer, and did not have the incentive of being closely followed up for research purposes. The improvement in permeability after treatment occurs during the period when the earliest morphological indices of response, the surface cell height and mitotic index, are also improving, ${ }^{17}$ but before complete morphological response can be expected, ${ }^{18}$ in agreement with earlier reports that functional improvement precedes histological recovery. ${ }^{18}$ Although ultrastructural changes in the basement membrane and sub-epithelial deposition of immune complexes have been observed within 48 hours of gluten challenge,$^{19}{ }^{20}$ the maximal change in intestinal permeability occurs two to four days after a single dose of gluten. This discrepancy may reflect the time taken for damaged cells to mature to a point on the mucosa where they have a greater influence on passive permeability, or it may be that permeability changes are the result of a separate mechanism, more delayed than immune complex deposition. Light microscopic evidence of a reduction in surface cell height and an increased mitotic index may be seen within seven days of gluten challenge,${ }^{17}$ coinciding with the increased permeability to cellobiose we have demonstrated, and the fall in cellobiose recovery after treatment of coeliac disease and rise after gluten challenge may be due to changes in epithelial integrity or cell turnover, affecting the 'leakiness' of the mucosa. The slow change in mannitol recovery after treatment may reflect the time taken for villous architecture and absorptive surface area to return to normal:

The variation between subjects in the speed with which they respond to a gluten challenge has been related to the quality of dietary control, ${ }^{19}$ the dose and form of gluten given, ${ }^{21}$ age $^{22}$ and the duration of treatment before challenge, those patients treated most recently responding more rapidly. ${ }^{17}$ Speed of response was not related to age or duration of treatment in our patients, and they were all given the same dose of commercial gluten, but the possibility cannot be excluded that those patients showing the most rapid changes in permeability were habitually consuming small quantities of gluten, although all denied knowingly doing so.

Low molecular weight polyethylene glycol (PEG 400 ) has been advocated as a probe molecule to demonstrate changes in intestinal permeability, the various subfractions showing a decreased absorption as the molecular weight increases. ${ }^{23}$ In coeliac disease there appears to be a general reduction in absorption with no increased permeability to the high molecular weight fractions $\mathrm{s}^{24}$ in contrast with our findings. All patients studied with PEG, however, had been treated with a gluten free diet, so the failure to demonstrate increased permeability to large molecules in these patients may have been the effect of treatment.

Measurement of mannitol and cellobiose recoveries by the use of separate assays may be considered inconvenient, and quantitative paper chromatography has been criticised for its inaccuracy. ${ }^{25}$ In our hands, how- 
ever, the technique is both accurate and reliable, and the precision is similar to that found by Menzies when using the technique to measure similar disaccharides. ${ }^{16}$

The use of cellobiose as a probe molecule is open to criticism, as it is partially hydrolysed by intestinal disaccharidases; this effect, however, is small and unlikely to affect these findings, as we have been unable to demonstrate any difference between recoveries of cellobiose and lactulose in normal or coeliac subjects, ${ }^{26}$ and patients with intestinal hypolactasia have normal test results. ${ }^{14}$ Hence the increased cellobiose absorption in untreated coeliac disease is not due to associated hypolactasia. Furthermore, the change in cellobiose recovery after treatment is unlikely to be due to recovery of intestinal disaccharidase, as enzyme levels revert to normal only after a prolonged period of gluten exclusion. ${ }^{22}$

The advantage of simultaneous administration of two probe molecules of different sizes is clearly demonstrated by the response to gluten challenge in which the cellobiose/mannitol recovery ratio of all patients became abnormal, whereas the effect on the recovery of either probe molecule alone failed to demonstrate such changes. Even the considerable increase in cellobiose recovery does not achieve statistical significance in this small group of patients, because of the wide variation between individuals, and it is unlikely that any other probe molecule used alone-as, for example, the xylose absorption test-would be sufficiently sensitive to demonstrate such unequivocal changes in permeability. The reproducibility of this test system is emphasised by the constant ratio of the controls, suggesting that changes in ratio reflect true changes in permeability.

Reliable oral tests of intestinal permeability may have important applications in coeliac disease. As well as being useful in reaching a diagnosis, ${ }^{14}$ such a test is of value in monitoring the effect of treatment, either confirming an early response or recognising 'nonresponding coeliac disease'. In the long-term it will detect those patients who relapse.

The test described here may be a major advance in the context of a gluten challenge; conventional gluten challenge is made difficult by several factors. Many patients are unwilling to abandon their diet, or to undergo further jejunal biopsy, and the optimum dose and nature of gluten to be given, and the duration of challenge, are unknown. The belief that failure to demonstrate relapse after three months' gluten challenge excludes the diagnosis of coeliac disease ${ }^{27}$ is no longer tenable, as relapse may occur after much longer periods. ${ }^{28}{ }^{29}$ The timing of a post-challenge jejunal biopsy is therefore difficult; symptomatic relapse is of little value in predicting histological relapse, which may be symptomatic, ${ }^{21}{ }^{27}{ }^{29}$ and previous screening tests - for example, one hour blood $x^{2}$ lose $^{21}$ - have not proved universally reliable. ${ }^{30}$ The cellobiose/mannitol ratio may be a sufficiently sensitive screening test to aid in the timing of a post-challenge biopsy.

The changes in intestinal permeability after a single dose gluten challenge, which we have demonstrated in each of a small group of patients with coeliac disease, are likely to be a direct result of gluten ingestion, although a double-blind trial comparing the effects of gluten on intestinal permeability with those of placebo may be necessary to confirm this. The use of this test to demonstrate such changes after a brief period of exposure to gluten may, if confirmed, offer a convenient and non-invasive alternative to jejunal biopsy in diagnosing gluten sensitivity.

IH is in receipt of a grant from the Leeds Teaching Hospital Special Trustees. IC was in receipt of a grant from the West Riding Research Fund. We are grateful to Mrs C L Baxendale for typing this manuscript.

\section{References}

1 Fordtran JS, Rector FC, Locklear TW, Ewton MF. Water and solute movement in the small intestine of patients with sprue. J Clin Invest 1967; 46:287-98.

2 Kivel RM, Kearns DH, Liebowitz D. Significance of antibodies to dietary proteins in the serum of patients with non-tropical sprue. N Engl J Med 1964; 271:769-72.

3 Menzies IS. Absorption of intact oligosaccharide in health and disease. Biochem Soc Trans 1974; 2:1042-7.

4 Cobden I, Dickinson RJ, Rothwell J, Axon ATR. Intestinal permeability assessed by excretion ratios of two molecules. Results in coeliac disease. Br Med J 1978; 2:1060.

5 Menzies IS, Laker MF, Pounder R, Bull J, Heyer S, Wheeler PG, Creamer B. Abnormal intestinal permeability to sugars in villous atrophy. Lancet 1979; 2:1107-9.

6 Alvarado F. D-xylose active transport in the hamster small intestine. Biochim Biophys Acta 1966; 112:292-306.

7 Lindemann B, Solomon AK. Permeability of luminal surface of intestinal mocosal cells. J Gen Physiol 1962; 45:801-10.

8 Smyth DH, Wright EM. Streaming potentials in the rat small intestine. J Physiol 1966; 182:591-602.

9 Fordtran JS, Rector FC, Ewton MF, Soter N, Kinney J. Permeability characteristics of human small intestine. $J$ Clin Invest 1965; 44:1935-44.

10 Nasrallah SM, Iber FC. Mannitol absorption and metabolism in man. Am J Med Sci 1969; 258:80-8.

11 Fromter E, Diamond J. Route of passive ion permeation in epithelia. Nature New Biol 1972; 235:9-13.

12 Wheeler PG, Menzies IS, Creamer B. Effect of hyperosmolar stimuli and coeliac disease on the permeability of the human gastro-intestinal tract. Clin Sci Mol Med 1978; 54:495-501.

13 Cobden I, Rothwell J, Axon ATR. Intestinal permeability in rats infected by Nippostrongylus brasiliensis. Gut 1979; 20:716-21.

14 Cobden I, Rothwell J, Axon ATR. Intestinal permeability and screening tests for coeliac disease. Gut 1980; 21:512-8.

15 Cobden I. University of Newcastle upon Tyne, The investigation of intestinal permeability, 1980. 
16 Menzies IS. Quantitative estimation of sugars in blood and urine by paper chromatography. J Chromatography 1973; 81:109-27.

17 Pollock DJ, Nagle RE, Jeejeebhoy KN, Coghill NF. The effect on jejunal mucosa of withdrawing and adding dietary gluten. Gut 1970; 11:567-75.

18 Macdonald WC, Brandborg LL, Flick AL, Trier JS, Rubin CE. Studies of coeliac sprue. IV. The response of the whole length of the small bowel to a gluten free diet. Gastroenterology 1964; 47:573-89.

19 Shiner M. Ultrastructural changes suggestive of immune reactions in the jejunal mucosa of coeliac children following gluten challenge. Gut 1973; 14:1-12.

20 Shiner M, Ballard J. Antigen antibody reactions in jejunal mucosa in childhood coeliac disease after gluten challenge. Lancet 1972; 1:1202-5.

21 Rolles CJ, McNeish AS. Standardised approach to gluten challenge in diagnosing childhood coeliac disease. $\mathrm{Br}$ Med J 1976; 1:1309-11.

22 Pena AS, Truelove SC, Whitehead R. Disaccharidase activity and jejunal morphology in coeliac disease. $Q J$ Med 1972; 41:457-76.

23 Chadwick VS, Phillips SF, Hoffman AF. Measurement of intestinal permeability using low molecular weight polyethylene glycols. I Chemical analysis and biological properties of PEG 400. Gastroenterology 1977; 73:241-46.

24 Chadwick VS, Phillips SF, Hoffman AF. Measurement of intestinal permeability using low molecular weight polyethylene glycols. II Application to normal and abnormal permeability states in man and animals. Gastroenterology 1977; 73:247-51.

25 Ukabam SO, Cooper BT. Sugaring the Crosby capsule. Lancet 1981; 1:725-6.

26 Cobden I, Rothwell J, Axon ATR. Non-invasive test for small intestinal mucosal damage. Lancet 1979; 2:1379.

27 Packer SM, Charlton V, Keeling JW, Risdon RA, Ogilvie D, Rowlatt RJ, Larcher VF, Harries JT. Gluten challenge in treated coeliac disease. Arch Dis Child 1978; 53:449-55.

28 McNicholl B, Egan-Mitchell B, Fottrell PF. Variability of gluten intolerance in treated childhood coeliac disease. Gut 1979; 20:126-32.

29 Kumar PJ, O'Donoghue DP, Stenson K, Dawson AM. Reintroduction of gluten in adults and children with treated coeliac disease. Gut 1979; 20:743-9.

30 Lamabadusuriya SP, Packer S, Harries JT. Limitations of the xylose tolerance test as a screening procedure in childhood coeliac disease. Arch Dis Child 1975; 50:34-9. 